\title{
Pressupostos pedagógicos das atuais propostas de formação superior em saúde no Brasil: origens históricas e fundamentos teóricos ${ }^{1}$
}

\author{
Solange de Fátima Reis Conterno \\ Roseli Esquerdo Lopes
}

Resumo: Busca-se demonstrar que as metodologias inspiradas em pressupostos pedagógicos não diretivos, difundidas pelo Ministério da Saúde como inovadoras no campo da formação em saúde, se contextualizadas historicamente, perdem sua inventividade e originalidade. Tomando-se como fonte documentos oficiais que reorientam a formação profissional em saúde no Brasil, analisou-se as principais iniciativas de mudança e identificou-se seus pressupostos: aprendizagem significativa, professor facilitador, aprender a aprender; aprendizagem ativa e aprendizagem por problemas. Conclui-se que tais princípios pedagógicos podem ser considerados inovações no contexto educacional em que foram produzidos, no início do século passado. Na saúde, também não se trata de uma novidade, pois a Medicina Preventiva, desde 1950, tem defendido a readequação curricular e a incorporação de metodologias ativas na formação profissional.

Palavras-chave: Educação superior em saúde. Metodologias ativas. Pedagogias não diretivas.

Pedagogical assumptions of current health-related higher education majors in Brazil: historical backgrounds and theoretical frameworks

Abstract: We aim at demonstrating how methodologies inspired by non-directive pedagogical assumptions - advertised by the Ministry of Health as innovative for nursing schools - lose their inventiveness and originality, if interpreted historically. We analyzed the main initiatives for change and their assumptions by taking specific documents as our source - ones that redirect the formation of health professionals in Brazil. Assumptions, hereby summarized, were: significant learning, teacher-facilitator, learning how to learn, active learning and learning through problems. Such pedagogical principles can be regarded as innovative only in the educational contexts where they were produced early last century. When it comes to Healthcare, it is not a novelty either, because preventive healthcare studies have defended both curricular readjustment and the incorporation of active methodologies in nursing school ever since 1950 .

Key words: Higher education in health. Active methodologies. Non-directive pedagogy approaches.

1 O presente artigo é resultado de pesquisa concluída de doutorado desenvolvida junto ao Programa de Pós-Graduação em Educação da Universidade Federal de São Carlos (UFSCar). 


\section{Introdução}

A problematização sobre o processo de formação dos profissionais que atuam na área da saúde no Brasil é necessária, pois a sua preparação técnica, humana, ética e científica é importante para a construção de um sistema de saúde que de fato priorize a qualidade da assistência à população.

O debate acerca dessa temática não é recente, articula-se aos movimentos de organização dos modelos de atenção à saúde, que produziram demandas, propostas e projetos de formação, decorrentes das necessidades e das perspectivas teóricas presentes nos diferentes momentos históricos. O referido debate não se limita aos espaços educativos formais, vem sendo arrolado, recorrentemente, por diferentes entidades ligadas à área ou ao campo da formação em saúde e que, ao longo das últimas décadas, produziram significativa discussão e encaminhamentos, os quais serviram de base para as decisões oficiais.

No Brasil, nos últimos anos, as sugestões de mudanças na formação podem ser verificadas em diferentes projetos e programas oficiais específicos, oriundos do Ministério da Saúde, nos quais há a defesa das inovações pedagógicas, expressas por diferentes metodologias de abordagens não diretivas, fomentando a adesão pelas Instituições de Ensino Superior (IES) a essas metodologias. Nesse movimento, percebe-se significativos investimentos, tanto financeiros quanto humanos, na direção de promover mudanças na formação dos profissionais que atuam na saúde.

Dentre os argumentos oficiais que reforçam a alteração no processo de formação em saúde, apresenta-se a necessidade das graduações atenderem a demandas das políticas atuais de saúde, no sentido de efetivar a inversão do modelo assistencial, formando profissionais para atuarem em programas focalizados na atenção básica em saúde, centrados em ações preventivas que abranjam amplos grupos populacionais. Potencializa-se a ideia de que a formação dos profissionais seria o principal obstáculo para a consolidação de um sistema de saúde de fato resolutivo e que a mudança de ordem metodológica, de referencial pedagógico, seria a prioridade nesse âmbito.

Tem sido divulgado e está se forjando um consenso de que os pressupostos pedagógicos inovadores expressos pelos lemas: "aprendizagem significativa"; "aprender a aprender"; "professor facilitador"; "metodologias ativas" e "aprendizagem por problemas" oferecem as bases teórico-metodológicas para promover processos de formação profissional mais críticos e adequados às necessidades do atual sistema de saúde.

Os referidos lemas pedagógicos possuem vínculos históricos que devem ser considerados ao serem tomados na atualidade. A "aprendizagem significativa", 
Pressupostos pedagógicos das atuais propostas de formação superior em saúde no Brasil: origens históricas e fundamentos teóricos

segundo Rogers (1971), seria toda aprendizagem autodescoberta ou a que os alunos tivessem dispostos a aprender, tendo sido amplamente divulgada na área da educação por David Ausubel (2002); o “aprender a aprender" defende que o mais importante seria o desenvolvimento de um método de aquisição do que realmente aprender conhecimentos sistematizados, sendo valorizado mais a atitude e o desejo de continuar aprendendo (ROGERS, 1971; DEWEY, 1979b); “professor facilitador", termo cunhado por Rogers na década de 1960, designando um professor que não direcionaria o processo de ensino, mas encorajaria vivências de aprendizagem ao aceitar o aluno tal como ele é. Esse pressuposto foi defendido e colocado em prática por Neill (1976); as "metodologias ativas" se amparam na ideia de que o ensino deve ser pela ação e não pela instrução, tendo o aluno como o centro do processo de ensino-aprendizagem, dentre seus divulgadores estão Cousinet (1959), Dewey (1978, 1979b), além de Decroly e Montesssori; o pressuposto da "aprendizagem por problemas" advoga que experiências ou atividades geradoras de problemas estimulariam a busca por conhecimentos, portanto, a aprendizagem (DEWEY, 1979a, 1979b).

Diante das questões destacadas, o objetivo central deste artigo é demonstrar que as metodologias inspiradas em pressupostos pedagógicos não diretivos, divulgadas pelo Ministério da Saúde como inovadoras no campo da formação superior em saúde e como a única possibilidade, na atualidade, de uma formação crítica e progressista, se contextualizadas historicamente, não se constituem em novidade, nem para a saúde e nem para a educação.

\section{Metodologia}

Os dados apresentados e problematizados emergiram de pesquisa documental, tendo como fontes primárias documentos oficiais que explicitaram reorientações para a formação dos profissionais da saúde: portarias; resoluções; relatórios; recomendações e discursos oficiais elaborados e divulgados por instituições, órgãos e pessoas ligadas ao tema no contexto internacional e nacional, tais documentos serão apresentados e detalhados ao longo deste texto.

Buscou-se aprofundar o estudo dos autores clássicos das pedagogias ativas, dentre eles destacaram-se as produções de Ausubel (2002); Dewey (1978, 1979a, 1979b); Neill (1976) e Rogers (1971), com o intuito de explicitar movimentos de continuidade e ruptura desse referencial pedagógico e as orientações para a reformulação da formação em saúde no Brasil; além de se considerar a produção de pesquisadores do campo da educação que se debruçam sobre essa temática. 
A exposição apresentará os antecedentes históricos mais importantes do movimento internacional de mudança na formação profissional em saúde, com destaque para o protagonismo de diferentes organismos internacionais na oferta de ideias para tanto, visando apreender as influências que levaram o Ministério da Saúde, nos últimos anos, a induzir propostas de formação respaldadas nas denominadas metodologias inovadoras, de caráter não diretivo, assim como identificar as origens teórico-metodológicas dos seus pressupostos pedagógicos.

\section{A formação profissional em saúde em debate: influências do movimento internacional}

Como resultado da sistematização e análise das fontes documentais primárias, é possível indicar que, a partir da década de 1950, a temática ligada às questões da formação de recursos humanos se destacou no campo da saúde. Um movimento internacional emergiu de forma organizada, dedicando-se à promoção do debate sobre currículo e elementos do processo de ensino-aprendizagem, especialmente aqueles relacionados ao ensino médico.

O movimento mundial de mudança da educação médica produziu consensos, para além da categoria específica, sobre quais elementos deveriam definir a formação em saúde. Desse processo, se originou o movimento de reorientação da graduação em saúde no Brasil, com o intuito de superar o modelo de formação profissional, considerado tradicional e inadequado, desenvolvido, de maneira geral, pelas IES.

O movimento internacional ganhou corpo por meio de conferências e seminários que consolidaram a criação e atuação de diversas entidades em âmbito mundial, regional e local, as quais passaram a conduzir a discussão e os encaminhamentos quanto à reorientação da formação profissional em saúde.

Dentre as instituições internacionais que ofereceram incentivos teóricos e financeiros, a Organização Pan-Americana da Saúde (OPAS) se destacou ao voltar-se sobre essa questão nos países da América Latina e Caribe, passando, desde 1950, a se configurar como instância técnica, expressando ideias das comunidades especializadas da área da saúde. No Brasil, outra instituição que teve significativa influência e que, nos últimos anos, tem promovido e patrocinado diversas iniciativas, no sentido de mudar a formação superior em saúde, é a Fundação Kellogg.

Passaram a ocorrer inúmeros eventos e publicações com relação ao tema, sendo a maioria pautada pelo debate em torno da educação médica, tendo sido emblemático o $1^{\circ}$ Congresso Pan-Americano de Educação Médica. Realizado 
Pressupostos pedagógicos das atuais propostas de formação superior em saúde no Brasil: origens históricas e fundamentos teóricos

em Lima (Peru), no ano de 1951, elencou e discutiu os problemas enfrentados pela educação médica e publicou documento explicitando orientações a serem seguidas pelos países (ORGANIZACIÓN PANAMERICANA DE LA SALUD, 1952).

Indicou-se a ampliação do ensino de Medicina Preventiva e Social, sendo que a graduação deveria possibilitar uma formação generalista aos futuros médicos, ficando a especialização para o nível de pós-graduação. As conclusões do Congresso propuseram encaminhamentos pedagógicos a serem seguidos pelas escolas, no sentido de:

Reduzir os programas de cada curso ao essencial. Estes programas devem ser totalmente desenvolvidos num certo número de horas previamente fixados. [...] Recomendar que o ensino seja o mais objetivo possível por meio de demonstrações e exercícios práticos. [...] Organizar seminários com a participação ativa dos estudantes (ORGANIZACIÓN PANAMERICANA DE LA SALUD, 1952, p. 35 , tradução nossa).

Esse Congresso lançou uma das ideias que mais tarde ganhou destaque no campo da formação profissional em saúde, a ênfase da formação no ensino da Medicina Preventiva, que requereria das escolas uma reorientação quanto à organização do currículo e dos aspectos pedagógicos.

$\mathrm{Na}$ sequência, dois outros eventos internacionais promovidos pela OPAS também marcaram essa discussão, sendo eles os Seminários de Medicina Preventiva realizados em Viña del Mar (Chile) e em Tehuacán (México).

O primeiro Seminário de Medicina Preventiva, realizado em 1955, concentrou a discussão nos programas e métodos de ensino apropriados à Medicina Preventiva; na formação e funções dos docentes e na organização dos departamentos de Medicina Preventiva.

Apontou-se às escolas a necessidade de se ajustar o número de estudantes às possibilidades técnicas e econômicas de um bom ensino; realizar uma seleção cuidadosa dos alunos (considerando suas condições de inteligência, conhecimentos básicos, caráter e habilidades) e de se formar médicos generalistas (OFICINA SANITÁRIA PANAMERICANA, 1957).

Quanto aos métodos de ensino mais adequados à formação em Medicina Preventiva, pontuou-se que as aulas expositivas deveriam ocupar a menor proporção nesse processo, dando-se maior ênfase ao desenvolvimento de seminários, discussões bibliográficas, trabalho ativo individual dos alunos em laboratórios, clínicas e em campo de prática (OFICINA SANITÁRIA PANAMERICANA, 1957). 
O Seminário realizado em Tehuacán (México), em 1956, seguiu os mesmos moldes do anterior, todavia, foi mais incisivo quanto aos métodos de ensino considerados mais adequados para a formação de um profissional comprometido com a Medicina Preventiva. Recomendou-se "[...] reduzir a um mínimo razoável as aulas e ampliar os métodos que dão ao aluno a oportunidade de praticar ativamente a Medicina Preventiva nos pacientes, em suas famílias e na comunidade [...]" (OFICINA SANITÁRIA PANAMERICANA, 1957, p. 17, tradução nossa).

Em suma, o discurso pedagógico que emergiu no contexto da divulgação da Medicina Preventiva já apresentava alguns pressupostos das denominadas pedagogias ativas, que, na atualidade, são tomadas como inovadoras e capazes de formar profissionais mais comprometidos, técnica e politicamente, com os problemas de saúde da população, pressupostos através dos quais se reforçava a centralidade da atividade do aluno, da aprendizagem ativa, em detrimento do quantitativo de aulas teóricas e expositivas.

Reforçando a lógica de formação de profissionais para a saúde divulgada pelos seminários de Medicina Preventiva, o II Plano Decenal de Saúde das Américas, referente ao período de 1971 a 1980, resultado da II Reunião Especial de Ministros da Saúde das Américas, ocorrida em Santiago (Chile) reiterou em seu documento final a proposta de reforma do ensino das profissões da área da saúde divulgada pela OPAS e OMS, sendo que essa formação deveria prever aspectos sociais, buscando reafirmar uma abordagem multidisciplinar dos problemas de saúde, por meio de um ensino baseado em problemas e não em disciplinas, a estratégia pedagógica para uma formação mais integral (ORGANIZACIÓN PANAMERICANA DE LA SALUD, 1973).

Outro evento importante em âmbito internacional foi a $1^{\text {a }}$ Conferência Mundial de Educação Médica (CMEM) promovida pela Federação Mundial de Educação Médica, ocorrida em Edimburgo (Escócia), no ano de 1988, tida como um marco do debate acerca da relevância da educação médica para a política mundial de saúde daquele contexto, em que se tomava a Atenção Primária em Saúde como foco (FEUERWERKER, 2006).

Atenção Primária em Saúde era entendida como assistência sanitária essencial baseada em métodos e tecnologias práticas, cientificamente fundados e socialmente aceitos, colocados ao alcance de todos os indivíduos a um custo que a comunidade e os países pudessem arcar, preservando o espírito de auto-responsabilidade e autodeterminação (OMS; UNICEF, 1978).

A dinâmica organizativa da $1^{\mathrm{a}} \mathrm{CMEM}$ propiciou a participação de diferentes regiões do mundo, decorrente de um processo preparatório. Nas Américas, tal 
Pressupostos pedagógicos das atuais propostas de formação superior em saúde no Brasil: origens históricas e fundamentos teóricos

processo foi singular; a discussão ocorreu por meio do Projeto EMA - Educação Médica nas Américas, desenvolvido no período de 1987 a 1989, patrocinado pela Fundação Kellogg, idealizado e implementado por Mário Chaves, então, consultor da referida entidade (CHAVES; ROSA, 1990).

As finalidades do Projeto EMA, além de promover a participação ativa das Américas na $1^{\mathrm{a}} \mathrm{CMEM}$, foi analisar a situação da educação médica com o intuito de identificar problemas e formular um plano de médio prazo para o desenvolvimento dessa formação (CHAVES; ROSA, 1990).

O processo de discussão e elaboração do Projeto EMA foi publicado no livro: “Educação Médica nas Américas: o desafio dos anos 90”, sob a organização de Mario Chaves e Alice Reis Rosa (CHAVES; ROSA, 1990), o qual apresentou a síntese das ideias sobre quais deveriam ser os novos rumos para a educação médica das Américas.

O Projeto EMA reforçou as orientações explicitadas nos Seminários sobre Medicina Preventiva e, novamente, os pressupostos do aprender a aprender; da aprendizagem ativa, respaldada na experiência imediata e significativa do sujeito, são alçados como alternativas pedagógicas adequadas para a formação em saúde, no sentido de superarem uma formação embasada na transmissão do conhecimento, em que o professor é responsável pela direção do processo ensino-aprendizagem. Por isso aprender a aprender deve ser parte integrante do processo ensino-aprendizagem nas escolas médicas. Estas devem proporcionar oportunidades para que os estudantes aprendam sozinhos e se capacitem para procurar informação (CHAVES; ROSA, 1990, p. 34).

Os consensos estabelecidos quanto à reforma da educação médica na região das Américas foram divulgados e direcionados a outras categorias profissionais que atuam na saúde, fato evidenciado por Marcos Kisil, então, Diretor de Programa da Fundação Kellogg: "O estudo EMA, embora dedicado à educação médica, em suas conclusões abrange temas aplicáveis a outras profissões" (CHAVES; ROSA, 1990, p. 18).

Em 1993, ocorreu a $2^{\mathrm{a}}$ CMEM, em Edimburgo, dela resultou o documento "Recomendações da II Conferência Mundial de Educação Médica", que expôs uma breve análise da conjuntura da saúde mundial e apresentou de forma mais explícita, os pressupostos pedagógicos "aprendizagem centrada no aluno" e a "autoaprendizagem" como elementos que deveriam guiar a reforma curricular. A capacitação pedagógica dos docentes da medicina apareceu, nas recomendações dos eventos, como uma das medidas para enfrentar os entraves da formação e também como possibilidade para promover uma prática formativa que fosse ancorada em princípios pedagógicos ativos (ORGANIZAÇÃO PAN-AMERICANA DA SAÚDE, 1994). 
As recomendações das duas Conferências Mundiais de Educação Médica se complementam e reforçam a lógica de que a atuação profissional deveria preferencialmente centrar-se na Atenção Primária em Saúde; a reforma curricular deveria priorizar a formação generalista e adotar metodologias de ensino respaldadas na aprendizagem ativa e centradas no interesse dos alunos.

\section{Mudanças na formação profissional em saúde: iniciativas em território nacional}

As muitas propostas de mudança da formação em saúde no Brasil estabeleceram alguma articulação teórica com os pressupostos anunciados em âmbito mundial pelo movimento que, desde a década de 1950, colocou como questão central a reorientação da formação dos profissionais da área.

De 1970 em diante, houve a emergência, mais institucionalizada, de propostas e projetos que já anunciavam a necessidade de readequação curricular, de mudança de pressupostos teórico-metodológicos por meio da adesão àqueles considerados inovadores e mais avançados para a formação em saúde.

No Brasil, diversos esforços foram envidados na construção da possibilidade de colaborar com as alterações propostas, a criação do CLATES, Centro Latino-Americano de Tecnologia Educacional em Saúde, pode ser identificada como uma iniciativa significativa nesse sentido.

Esse Centro foi criado em 1972, fruto de um convênio firmado entre a OPAS e o governo brasileiro, junto à Universidade Federal do Rio de Janeiro (UFRJ), visando desenvolver atividades de serviços diretos e consultorias de aplicação do conhecimento científico ao processo de ensino-aprendizagem, por meio de recursos tecnológicos e de produção de materiais didáticos, a fim de facilitar o uso de métodos e meios educativos novos (ORGANIZACIÓN PANAMERICANA DE LA SALUD, 1983).

O CLATES integrou, até 1983, a estrutura do NUTES, Núcleo de Tecnologia Educacional em Saúde, órgão ligado à UFRJ; segundo Pires-Alves (2011), a criação do CLATES/NUTES pode ser entendida como parte das estratégias operacionais e das políticas regionais da OPAS na divulgação das orientações mais gerais do movimento mundial de reorientação da formação de recursos humanos em saúde e da divulgação da Pedagogia Médica.

A Pedagogia Médica foi um movimento que partiu das avaliações realizadas na década de 1950 sobre a formação na área e uma estratégia para efetivar a reforma da educação no setor da saúde, centralmente pela incorporação de novos métodos e meios de ensino (PIRES-ALVES, 2011). 
Edward Mervin Bridge, professor da Escola de Medicina da Universidade do Estado de Nova York (Buffalo) e consultor em educação da OPAS tornou-se, na década de 1960, a referência da Pedagogia Médica. O livro "Pedagogía Médica", de sua autoria, foi traduzido, em 1965, e divulgado junto às escolas latino-americanas ligadas à saúde, como uma produção técnica da OPAS.

A Pedagogia Médica, expressa nas 336 páginas do livro de Bridge, enfatizou que um bom professor de medicina seria aquele que desenvolvesse o ensino tendo como foco o interesse do aluno, levando os estudantes a aprender a aprender, a aprenderem guiados pelos interesses e iniciativas pessoais.

Com relação ao processo de ensino, a obra pontuou que a experiência vivenciada pelo aluno deveria ser o eixo condutor do processo de aprendizagem. A experiência sensorial do aluno como meio para apreensão do conteúdo escolar é um dos pressupostos centrais na Pedagogia Médica.

Não há dúvida de que o método mais eficaz para aprender é viver uma intensa experiência pessoal. Se cada estudante de medicina pudesse passar pela experiência de ter o seu próprio filho e viver os problemas da gravidez e do parto, cada um aprenderia muito sobre obstetrícia, mesmo sem um livro didático. [...] Também poderia ser proveitoso que cada cirurgião periodicamente sofresse uma operação, que cada residente ocasionalmente tomasse uma overdose de digitalina, e cada dermatologista sofresse de uma doença de pele (BRIDGE, 1965, p. 106, tradução nossa).

Buscava com ela superar a forma pela qual ocorria a graduação profissional, passando a divulgar pressupostos pedagógicos em que a ênfase sairia do ensino para a aprendizagem, do professor para o aluno, indicando outra abordagem pedagógica para o referido processo (BRIDGE, 1965).

Outra iniciativa que ganhou destaque no território nacional foi o Programa UNI; proposta lançada em 1991 pela Fundação Kellogg, que visava iniciar um novo programa em continuidade à sua estratégia de ajuda financeira aos países periféricos ${ }^{2}$.

Segundo Kisil e Chaves (1994), respectivamente, coordenador de área e consultor da Fundação Kellogg, o programa partiu da avaliação das experiências da proposta Integração Docente-Assistencial (IDA), visando maior articulação na educação dos profissionais de saúde e incorporando, nos novos projetos, a comunidade de forma destacada. Além de defender a inserção precoce dos

2 A ajuda oferecida pela Fundação Kellogg aos países ampara-se na lógica da cooperação internacional, ajuda financeira articulada à oferta de ideias para os vários setores das economias periféricas. A política de cooperação internacional emergiu no contexto da Guerra Fria, como estratégia dos EUA, para garantir a continuidade de sua posição de líder na economia capitalista mundial (LEHER, 1998). 
estudantes na realidade dos serviços de saúde, por meio de atividades de extensão universitária e atuação em centros de saúde experimentais, geralmente, periféricos ou rurais (SANTANA et al., 1999).

A partir da avaliação crítica das experiências da IDA, em 1991, a Fundação Kellogg divulgou o Programa UNI: Uma Nova Iniciativa na Educação dos Profissionais da Saúde: União com a Comunidade, dando continuidade à proposição anterior, com vistas a uma maior articulação entre o ensino das várias profissões que atuam no setor saúde e incorporando a comunidade (KISIL; CHAVES, 1994).

O início dos trabalhos do Programa UNI ocorreu em 1991, com a distribuição de cartas-convites a 800 universidades da América Latina. Cada instituição interessada deveria aderir aos princípios do programa, afirmando seu compromisso de mudança institucional para garantir uma efetiva parceria entre serviços, universidade e comunidade, além de explicitar a estratégia para conservar o projeto mesmo após o término do financiamento (FUNDAÇÃO KELLOGG, 1991).

No Brasil, no ano de 1991, foram selecionadas, inicialmente, quatro IES localizadas em: Botucatu (SP), Brasília (DF), Londrina (PR) e Marília (SP), as quais foram convidadas a fazer parte da implementação dos Projetos. Mais tarde, foram incluídas mais duas instituições localizadas nas cidades de Natal (RN) e Salvador (BA).

Quanto à metodologia de ensino, três aspectos deveriam caracterizar os Projetos UNI, sendo eles, a diversificação dos locais de ensino-aprendizagem, o treinamento em serviço e as experiências de aprendizagem em equipes multiprofissionais. $\mathrm{O}$ processo de aprendizagem centrava-se nas experiências vivenciadas pelos estudantes em espaços não convencionais. A aprendizagem ativa seria um dos seus princípios fundamentais. "[...] porque a aprendizagem ativa é uma exigência da velocidade do progresso e da desatualização dos conhecimentos. Há quem considere que um dos propósitos principais dos cursos de graduação é estimular os alunos a assumirem a responsabilidade por seu aprendizado [...]" (ROSA, 1994, p. 32).

A diminuição da dimensão teórica do ensino, a autoaprendizagem e a adesão a novas metodologias de ensino são indicadas, pelo movimento UNI, como a possibilidade de modernizar a formação "[...] com diminuição do ensino em aulas teóricas, e introdução de novas metodologias de ensino tais como ensino tutorial e em pequenos grupos, aprendizagem baseada em problemas (ABP), e estudo autodirigido [...]" (CHAVES et al., 1999, p. 174).

As principais mudanças sugeridas pelos Projetos UNI no processo de formação superior em saúde relacionam-se à reforma nos currículos, com a superação 
Pressupostos pedagógicos das atuais propostas de formação superior em saúde no Brasil: origens históricas e fundamentos teóricos

da concepção disciplinar dos currículos; com a adesão as metodologias ativas de aprendizagem e com a aprendizagem centrada no aluno (CHAVES et al., 1999).

No contexto da reorientação da formação em saúde no Brasil, a Rede UNIDA destacou-se como entidade que estabeleceu consensos quanto à necessidade de mudança, vinculada ao movimento promovido pela Fundação Kellogg, que, dos anos de 1980 em diante, passou a incentivar a organização em redes de trabalhos das experiências e iniciativas de mudança na formação em saúde.

Com o propósito de se firmar e de ser reconhecida enquanto ator social, visando influir nas políticas do setor, a Rede UNIDA empenhou-se na divulgação ampla de experiências formativas, consideradas inovadoras, desenvolvidas pelos membros da Rede, em eventos importantes da área de saúde e de formação, com o intuito de demonstrar a necessidade e a possibilidade de mudança na formação profissional (FEUERWERKER et al., 2000).

O exemplo mais notável desse movimento foi o trabalho em torno da proposta de diretrizes curriculares nacionais para as profissões "da saúde"3. Diante do Edital n ${ }^{\circ}$ 04/97, que convocou todas as IES a enviarem propostas de diretrizes curriculares nacionais às comissões de especialistas da Secretaria de Educação Superior (SESu), a Rede UNIDA, produziu o documento denominado: "Contribuição para as novas diretrizes curriculares dos cursos de graduação da área de saúde", que foi encaminhado às comissões de especialistas e à Câmara de Educação Superior do Conselho Nacional de Educação, apresentando as diretrizes gerais para a formação dos profissionais da saúde

O documento reafirmou os princípios pedagógicos que vinham permeando as proposições feitas pelos movimentos em torno da educação médica, há décadas. Era explícita a indicação incisiva de que os projetos político-pedagógicos das graduações deveriam se pautar por currículos fundamentados no humanismo e em metodologias ativas, tendo o aluno como centro do processo de ensino e aprendizagem, tomando o aprender a aprender e o aprender fazendo como pressupostos mais adequados para formar futuros profissionais (REDE UNIDA, 1998):

A educação de adultos pressupõe a utilização de metodologias ativas de ensino e aprendizagem, que proponham concretamente desafios a serem superados pelos estudantes, tendo o professor como facilitador e orientador do processo. [...] e considerando também que os conhecimentos, habilidades e atitudes exigidas do profissional

3 De acordo com a Resolução do Conselho Nacional de Saúde, n 287, de 08 de outubro de 1998, as categorias profissionais que atuam na área de saúde e que possuem formação de nível superior, são: Biomedicina, Ciências Biológicas, Educação Física, Enfermagem, Farmácia, Fisioterapia, Fonoaudiologia, Medicina, Medicina Veterinária, Nutrição, Odontologia, Psicologia, Serviço Social e Terapia Ocupacional (BRASIL, 1998). 
modificam-se rapidamente, temos que um dos objetivos de aprendizagem fundamentais do curso de graduação é o aprender a aprender (REDE UNIDA, 1998, p. 14).

A Rede UNIDA influenciou a elaboração dos elementos centrais das Diretrizes Curriculares Nacionais (DCN's) da área da saúde; é exemplar a solicitação do então coordenador da Rede, professor Márcio Almeida, ao Conselho Nacional de Educação, de que as competências e habilidades gerais das referidas diretrizes fossem iguais em todas as graduações ligadas a área da saúde (RODRIGUES, 2005).

Pela sistematização e análise das DCN's dos cursos de graduação da saúde aprovadas $^{4}$, é possível afirmar que o pedido foi atendido, pois dos 14 cursos, 11 deles: Biomedicina, Enfermagem, Farmácia, Fisioterapia, Fonoaudiologia, Medicina, Medicina Veterinária, Nutrição, Odontologia, Psicologia e Terapia Ocupacional reproduziram na íntegra as competências e habilidades gerais sugeridas pela Rede UNIDA no documento "Contribuição para as novas diretrizes curriculares dos cursos de graduação da área de saúde" (REDE UNIDA, 1998).

Diante do exposto, fica evidente como a Rede UNIDA veio construindo a possibilidade de se constituir como articuladora das mudanças na formação em saúde, além de se tornar defensora e divulgadora de consensos teórico-metodológicos que se explicitaram nas DCN's para as graduações em saúde.

\section{Origens dos pressupostos pedagógicos divulgados como inovadores na formação em saúde no Brasil}

De 2002 em diante, o Ministério da Saúde passou a desempenhar de forma mais efetiva seu papel constitucional de ordenador da formação de recursos humanos na área da saúde e tomou por fio condutor a indicação da urgente reorientação do processo formativo, dos currículos das graduações em saúde.

4 As DCN's analisadas no estudo foram publicadas por meio de Resoluções do Conselho Nacional de Educação e da Câmara de Ensino Superior, sendo: Resolução no 3 de 07/11/2001 da graduação em Enfermagem; Resolução n 4 de 07/11/2001 da graduação em Medicina; Resolução no 5 de 07/11/2001 da graduação em Nutrição; Resolução n ${ }^{\circ} 2$ de 19/02/2002 da graduação em Farmácia; Resolução no 3 de 19/02/2002 da graduação em Odontologia; Resolução no 4 de 19/02/2002 da graduação em Fisioterapia; Resolução $n^{\circ} 5$ de 19/02/2002 da graduação em Fonoaudiologia; Resolução nº 6 de 19/02/2002 da graduação em Terapia Ocupacional; Resolução n ${ }^{\circ} 7$ de 11/03/2002 da graduação em Ciências Biológicas; Resolução $n^{\circ} 15$ de 13/03/2002 da graduação em Serviço Social; Resolução no 1 de 18/02/2003 da graduação em Medicina Veterinária; Resolução n ${ }^{\circ} 2$ de 18/02/2003 da graduação em Biomedicina; Resolução no 7 de 31/03/2004 da graduação em Educação Física; Resolução no 8 de 07/05/2004 da graduação em Psicologia (ALMEIDA, 2003; BRASIL, 2002a, 2002b). 
Pressupostos pedagógicos das atuais propostas de formação superior em saúde no Brasil: origens históricas e fundamentos teóricos

Passou-se a difundir que a reforma do processo formativo deveria superar aquelas experiências educativas que, de certa forma, se identificavam com a proposta flexneriana ${ }^{5}$, em que currículos organizam-se em disciplinas hierarquizadas, de conteúdos técnico-científicos com perspectiva biológica marcante, levando à especialização e à prática centrada na atenção hospitalar, sob o argumento de que o referido modelo de formação seria inadequado por favorecer uma formação acrítica e restrita aos profissionais, não os capacitando para lidar com os problemas de saúde mais emergentes da população.

Outro elemento associado à ideia de reformar o ensino superior em saúde é a mudança de ordem metodológica, de referencial pedagógico. A inovação pedagógica em muitos projetos é tida como a questão central para alavancar a mudança do processo pelo qual a assistência à saúde é produzida no país.

Nesse sentido, o Programa Nacional de Incentivos às Mudanças Curriculares de Medicina (Promed), a Política Nacional de Educação Permanente em Saúde, as Diretrizes Curriculares Nacionais das graduações em saúde e, mais recentemente, o Programa Nacional de Reorientação da Formação Profissional em Saúde (Pró-Saúde) e o Programa de Educação pelo Trabalho para a Saúde (Pet-Saúde) passaram a divulgar que a adesão a pressupostos pedagógicos inovadores seria a possibilidade de preparar futuros profissionais capazes de atenderem às demandas da política atual em saúde, na qual a focalização das ações assistenciais na atenção básica em saúde é a orientação (BRASIL, 2002c, 2004, 2007, 2011).

Os pressupostos pedagógicos tomados como inovadores e recomendados como centrais pelo movimento de reorientação da formação profissional em saúde no Brasil, em diferentes propostas formativas ao longo dos últimos anos, podem ser verificadas no quadro a seguir, organizado a partir das fontes aqui trazidas.

É possível inferir que os princípios pedagógicos acima destacados, alicerces das propostas formativas em saúde na atualidade, se articulam aos referenciais teórico-metodológicos das pedagogias ativas de caráter não diretivo.

A não diretividade pedagógica está ligada teoricamente à Pedagogia Ativa, movimento que surgiu no final do século XIX, na Europa e nos Estados Unidos da América, como contraposição à Pedagogia Tradicional. A Pedagogia Ativa propôs uma mudança radical na educação, ao colocar o estudante, suas necessidades e capacidades no centro do processo educativo; ao enfatizar a atividade como precedente ao conhecer, em que o ambiente e não o saber sistematizado torna-se central na aprendizagem (CAMBI, 1999).

5 Emanada do Relatório que Abraham Flexner produziu em 1910 ao avaliar a qualidade das escolas médicas dos Estados Unidos e do Canadá. 
Quadro 1 - Princípios pedagógicos divulgados por diferentes iniciativas de mudanças na formação profissional em saúde no Brasil

\begin{tabular}{|c|l|}
\hline PRINCíPIOS PEDAGÓGICOS & \multicolumn{1}{c|}{$\begin{array}{c}\text { INICIATIVAS DE REORIENTAÇÃO } \\
\text { DA FORMAÇÃO EM SAÚDE NO BRASIL }\end{array}$} \\
\hline Aprendizagem significativa & $\begin{array}{l}\text { - Pedagogia Médica divulgada pelo CLATES/NUTES; } \\
\text { - Política Nacional de Educação Permanente em Saúde }\end{array}$ \\
\hline \multirow{3}{*}{ Professor facilitador } & $\begin{array}{l}\text { - Pedagogia Médica divulgada pelo CLATES/NUTES; } \\
\text { - Rede UNIDA; } \\
\text { - Diretrizes Curriculares Nacionais em saúde; } \\
\text { - PROMED; } \\
\text { - Pró-Saúde }\end{array}$ \\
\hline Aprender a aprender & $\begin{array}{l}\text { - Rede UNIDA; } \\
\text { - Diretrizes Curriculares Nacionais em saúde; }\end{array}$ \\
\hline - Pró-Saúde
\end{tabular}

Nesse sentido, o pressuposto da aprendizagem significativa articula-se ao referencial de autores defensores da não diretividade pedagógica; um dos seus difusores foi Carl Ransom Rogers (1902-1987), psicólogo norte-americano, precursor da Psicologia Humanista, que sistematizou o método da Terapia Centrada no Cliente, ou também Abordagem Centrada na Pessoa.

Rogers indicou que a aprendizagem significativa seria toda aprendizagem autodescoberta/autodirigida, aquela com sentido imediato para os sujeitos envolvidos e quando " [...] o estudante percebe que a matéria a estudar se relaciona com seus próprios objetivos [...] uma pessoa só aprende significativamente aquelas coisas que percebe implicarem na manutenção ou na elevação de si mesma" (ROGERS, 1971, p. 154).

Para Rogers (1971), os seres humanos têm naturalmente potencialidade de aprender, os traços da personalidade, hábitos e forma de pensar, encontram-se prontos por ocasião do nascimento. Os sujeitos aprendem algo que se relaciona com os seus próprios objetivos, ao professor caberia a função de promover um clima favorável de liberdade para facilitar a aprendizagem.

No campo específico da Psicologia da Educação, David Paul Ausubel (19182008), psicólogo estadunidense, na década de 1970 trabalhou com o conceito 
Pressupostos pedagógicos das atuais propostas de formação superior em saúde no Brasil: origens históricas e fundamentos teóricos

de aprendizagem significativa, reforçando o pressuposto da não diretividade pedagógica.

Como desdobramento do princípio da aprendizagem significativa, o conceito de professor facilitador emerge, igualmente, no campo da formação em saúde. Nos diversos documentos analisados há uma evidente crítica ao papel do professor como aquele que seleciona e organiza a transmissão do saber constituído. Indica-se que o desejável para um processo de formação democrático seria o de facilitador da aprendizagem, aquele que possibilitasse um clima favorável para que o aluno tenha, de forma ativa, uma postura crítica e reflexiva.

A origem teórico-metodológica do conceito professor facilitador também está nas indicações das pedagogias não diretivas e, especificamente, na produção de Carl Rogers (1971). O termo professor facilitador foi para expressar uma relação pedagógica centrada no interesse e na atividade dos alunos.

Na obra Liberdade para Aprender, Rogers (1971) afirma que a função do professor facilitador é produzir um clima na sala de aula que permitisse a aprendizagem natural, desenvolvendo uma relação de empatia com o aluno, da aceitação tal como ele é, da compreensão de suas atitudes e sentimentos captando seus interesses e vontades.

Alexander Sutherland Neill (1883-1973) também defende a concepção de professor facilitador, principalmente em Liberdade sem Medo, obra lançada em 1960, que relatou a experiência educacional desenvolvida em Summerhill. Para Neill, o professor deveria centrar seu trabalho no interesse do aluno, não influenciando ou transmitindo conceitos: "[...] professores acham-se na obrigação de influenciar as crianças porque pensam saber o que a criança deve ter, deve aprender, deve ser. Discordo" (NEILL, 1976, p. 238).

Ao apresentar os fundamentos do princípio pedagógico "professor facilitador", foi possível perceber como os pressupostos do "aluno como centro do processo educativo" e da "aprendizagem ativa" se articulam teoricamente, reforçando a dicotomia entre o processo de ensino-aprendizagem, valorizando demasiadamente a "figura" do aluno, em detrimento da valorização do papel do professor no processo educativo.

Nos textos das DCN's das graduações em Biomedicina; Enfermagem; Farmácia; Fisioterapia; Fonoaudiologia, Medicina; Medicina Veterinária; Nutrição; Odontologia e Terapia Ocupacional há a afirmação de que tais cursos deveriam ter um Projeto Político Pedagógico "centrado no aluno como sujeito da aprendizagem e apoiado no professor como facilitador”, essa questão é apresentada igualmente no artigo $9^{\circ} \mathrm{em}$ todas as Diretrizes.

Outro princípio pedagógico amplamente divulgado foi o "aprender a aprender", que é considerado uma das competências gerais dos profissionais 
articulada à educação permanente, em que os profissionais da saúde precisariam ser capazes de aprender continuamente, devendo aprender a aprender e ter responsabilidade com a educação das novas gerações profissionais.

O Pró-Saúde, em diferentes documentos, divulga que um dos objetivos das graduações é o aprender a aprender, sob o argumento de que no mundo atual, a velocidade com que são produzidos os conhecimentos e tecnologias exige mais habilidades pessoais para a busca de informações em diversas fontes (BRASIL, 2007).

Rogers na década de 1970 já havia definido o "aprender a aprender" como a finalidade da educação no mundo moderno, como a possibilidade, por excelência, de se efetivar o verdadeiro papel da escola: "O único homem que se educa é aquele que aprendeu como aprender” (ROGERS, 1971, p. 104). Assim, conforme o referencial pedagógico não diretivo, o foco é a aprendizagem, o aluno como o centro desse processo, sendo o ato de ensinar, de transmitir o conhecimento historicamente produzido pela humanidade, secundarizado.

O referido princípio tornou-se uma palavra de ordem originada nas pedagogias não diretivas, radicadas, particularmente, no "escolanovismo", movimento educacional de renovação do ensino que partiu da crítica contundente aos pressupostos teórico-metodológicos da escola tradicional, principalmente a forma como eram encaminhados os conteúdos e a maneira como eram considerados e tratados os alunos pela organização escolar e por parte dos professores. Tal movimento surgiu no início do século XX, nos países centrais com importantes repercussões no Brasil (CAMBI, 1999).

Outo príncipio pedagógico divulgado nos programas e projetos oficiais também está alicerçado nos métodos da Pedagogia Ativa é o da aprendizagem por problemas, colocado como antagonista do método de ensino de exposição pelo professor.

Zanotto e De Rose (2003) identificam quatro abordagens diferentes acerca do conceito e da utilização de problematização no processo de ensino-aprendizagem, sendo elas divulgadas pelas produções teóricas de: Dewey (1979a, 1979b), Ausubel (2002), Freire (1989) e Saviani (1991). Apesar disso, seria uma imprecisão téorica estabelecer identidade entre os pressupostos teórico-metodológicos dos autores citados.

A aprendizagem por problemas fundamenta dois métodos de ensino divulgados e assimilados no campo da saúde no Brasil, sendo eles: a Aprendizagem Baseada em Problemas ou Problem Based Learning (PBL) e a Metodologia da Problematização, ambos com características peculiares.

A Aprendizagem Baseada em Problemas (PBL) é divulgada pelos documentos orientadores da formação em saúde no Brasil como uma das estraté- 
Pressupostos pedagógicos das atuais propostas de formação superior em saúde no Brasil: origens históricas e fundamentos teóricos

gias inovadoras no que tange a metodologias de ensino superior. Contudo, a recomendação da utilização da PBL não é nova, sendo que estava presente nas discussões e recomendações dos movimentos internacionais já na década de 1950 e teve suas primeiras experiências na década de 1960 na Universidade de Maastricht, Holanda, e, com maior impacto, na Faculdade de Medicina da Universidade McMaster, Canadá, sob a influência da metodologia do estudo de casos empregada nos anos de 1920, pela Escola de Direito de Harvard (BARROS; LOURENÇO, 2006).

Berbel (1998), ao aprofundar o estudo acerca da aprendizagem por problemas concluiu que a "Aprendizagem Baseada em Problemas tem como inspiração os princípios da Escola Ativa, do Método Científico, de um Ensino Integrado e Integrador dos conteúdos, dos ciclos de estudos e das diferentes áreas envolvidas, em que os alunos aprendem a aprender [...]” (p. 152).

A Metodologia da Problematização tem sido divulgada como uma estratégia pedagógica com potencialidade para formar profissionais de saúde mais críticos e capazes de enfrentarem os desafios postos pela realidade social.

A referência teórica mais citada sobre a Metodologia da Problematização no campo da formação em saúde no Brasil, tem sido o denominado Método do Arco de Charles Maguerez, divulgado pelo esquema apresentado por Bordenave e Pereira (1991) e pela produção de Berbel (1998, 1995).

Charles Maguerez educador francês trabalhou com mineiros, agricultores e operários analfabetos, em países subdesenvolvidos ou recém-independentes, localizados na Europa e África. Relatou sua experiência educativa no livro "La promotion technique du travailleur analphabete", publicado em 1966. Na década de 1970, Maguerez prestou consultoria ao Brasil, na realização de diagnóstico de treinamento de técnicos agrícolas do estado de São Paulo (BERBEL, 2012).

A proposta pedagógica da problematização da aprendizagem, do Arco de Maguerez, está calcada nos princípios da Pedagogia Ativa, em que a aprendizagem não é guiada por objetivos educacionais definidos e nem delimita expectativas quanto à aprendizagem; o professor deve ser facilitador tendo a função de organizar o grupo para que busque as informações, conhecimentos, avaliados como necessários para resolver dado problema. A imprevisibilidade é uma marca peculiar desse método de ensino.

Ao apresentar os fundamentos teóricos dos pressupostos pedagógicos difundidos no campo da formação superior em saúde como inovadores, evidencia-se a significativa influência do pensamento das Pedagogias Ativas, respaldados nos ideais do escolanovismo, movimento que desde o século passado tem influenciado o campo da educação. 


\section{Considerações Finais}

Lidar com o fato de que nem sempre aquilo que se denomina como novo é uma novidade, ou traz em si um progresso significativo em relação ao já estabelecido, auxiliou no entendimento e na demonstração de que os pressupostos pedagógicos não diretivos, divulgados pelo Ministério da Saúde como inovadores no campo da formação em saúde e como a possibilidade, na atualidade, de uma formação em saúde mais crítica, se contextualizados historicamente, não se constituem em novidade nem na saúde e nem na educação.

A aprendizagem significativa, o professor faciliador, o aprender a aprender, a metodologia ativa de aprendizagem e a aprendizagem por problemas, como aqui demonstrado, são os pressupostos pedagógicos basilares das autodenominadas metodologias inovadoras, as quais passaram a ser ungidas como representantes do que seria mais avançado, moderno e politicamente responsável no campo da formação em saúde.

Contudo, na saúde não é uma novidade a proposição da reforma curricular com a incorporação de metodologias ativas ao processo formativo. Um dos movimentos considerados mais politizados e progressistas na área, o da Medicina Preventiva, datado na metade do século passado, pode ser considerado o elemento remoto que influenciou a construção das propostas atuais de formação em saúde no Brasil. Tal constatação ajuda a entender porque o movimento de mudança da formação em saúde, por meio da adesão aos pressupostos pedagógicos ativos/inovadores, ganhou o status de proposta formativa "mais crítica e progressista" que a saúde produziu.

Por outro lado, os princípios pedagógicos divulgados como inovadores e modernos pelos programas atuais de reorientação da formação em saúde retomam os preceitos do movimento renovador da escola, que surgiu no início do século XX, nos países centrais, fundamentalmente na Europa e Estados Unidos, o qual entendia que o aluno deveria ser o centro do processo de ensino-aprendizagem; os métodos de aprendizagem deveriam ser ativos e criativos, fixados no interesse do aluno; a aprendizagem como uma atividade significativa e de descoberta teria, a não diretividade pedagógica como eixo das práticas educativas.

Tais princípios pedagógicos podem ser considerados inovações no contexto em que foram produzidos, por terem sido respostas dirigidas aos problemas enfrentados no campo da educação, principalmente, no início do século passado e, que tinham como questão central a educação básica. No entanto, na atualidade tais pressupostos são ressignificados/atualizados, perdendo seu sentido originário. 
Pressupostos pedagógicos das atuais propostas de formação superior em saúde no Brasil: origens históricas e fundamentos teóricos

O foco das mudanças da formação profissional em saúde no Brasil incidiu nos aspectos organizativos do processo ensino-aprendizagem, nos aspectos pedagógicos. A modernização didática é tomada como elemento determinante da mudança da formação. Modernizar o ensino em saúde passou a ser sinônimo de redução da carga horária de aulas teóricas, de superação da concepção disciplinar do currículo, de desenvolvimento do ensino tutorial, da ênfase na aprendizagem ativa e significativa, tendo o aluno como centro e o professor como um facilitador, além da adoção dos métodos de ensino baseados em resolução de problemas, expresso pela Metodologia da Problematização ou pela Aprendizagem Baseada em Problemas.

No campo da formação em saúde, o conceito de tradicional acabou sendo amplamente divulgado como adjetivo do profissional ou da instituição que não aderiu à lógica dos programas oficiais. Não falar, não escrever ou não defender as possíveis positividades das metodologias ativas, da aprendizagem significativa, do professor facilitador, da aprendizagem por problema tornou-se quase um delito na área.

A reflexão sobre a formação em saúde deverá considerar não só o método, as propostas pedagógicas, inovadoras ou não, mas as possibilidades que tais propostas oferecem para se compreender e resolver a complexidade dos processos saúde-doença na atualidade; ou seja, a discussão central não é de ordem metodológica e sim, primariamente, de ordem epistemológica (CUTOLO; DELIZOICOV, 2003).

A não compreensão das origens teórico-metodológicas dos pressupostos pedagógicos divulgados pelos programas oficiais pode levar à mera reprodução dos conceitos ou a adesão apenas instrumental. Há uma tendência presente na formação profissional em saúde, que tem produzido certa confusão teórica, a qual trata concepções/conceitos diferentes como semelhantes. $\mathrm{O}$ não exame dos fundamentos teóricos de dada opção metodológica pode levar a uma prática formativa ingênua, inconsequente e imprecisa, que sem uma direção definida poderá inviabilizar o objetivo central do ato educativo.

\section{Referências}

ALMEIDA, Márcio José. (Org.). Diretrizes curriculares nacionais para os cursos universitários da área da saúde. Londrina: Rede Unida, 2003.

AUSUBEL, David Paul. A adquisición y retención del conocimiento: uma perspectiva cognitivista. Barcelona: Paidós, 2002. 
BARROS, Nelson Felice; LOURENÇO, Lídia. Almeida. O ensino da saúde coletiva no método de aprendizagem baseado em problemas: uma experiência da Faculdade de Medicina de Marília. Rev. bras. educ. med., Rio de Janeiro, v. 30, n. 3, p. 136-146, 2006.

BERBEL, Neusi Aparecida Navas. Metodologia da Problematização: uma alternativa apropriada para o ensino superior. Semina - Ci. Soc.Hum, Londrina, v. 6, n. 2, Ed. Especial, p. 9-19, out. 1995.

BERBEL, Neusi Aparecida Navas. A problematização e a aprendizagem baseada em problemas: diferentes termos ou diferentes caminhos? Interface - Comunic., Saúde, Educ. Botucatu, v. 2, n. 2, p. 139-154, 1998.

BERBEL, Neusi Aparecida Navas. A Metodologia da Problematização em três versões no contexto da didática e da formação de professores. Rev. Diálogo Educ, Curitiba, v. 12, n. 35, p. 103-120, jan./abr. 2012.

BORDENAVE, Juán Dias; PEREIRA, Adair Martins. Estratégias de ensino-aprendizagem. 12. ed. Rio de Janeiro: Vozes, 1991.

BRASIL. Conselho Nacional de Saúde. Resolução № 287, de 08 de outubro de 1998. Relaciona as categorias profissionais de saúde de nível superior. Brasília, 1998a. Disponível em: < http://www.crefrs.org.br/legislacao/pdf/ resol_cns_287_1998.pdf>. Acesso em: 12 abr. 2013.

BRASIL. Ministério da Educação. Conselho Nacional de Educação. Câmara de Educação Superior. Resolução CNE/CES n ${ }^{\circ}$ 7, de 11 de março de 2002. Institui Diretrizes Curriculares Nacionais do Curso de Graduação em Ciências Biológicas. Brasília, 2002a. Disponível em: $<$ http://portal.mec.gov. br/cne/arquivos/pdf/CES07-2002.pdf>. Acesso em: 10 jun. 2013.

BRASIL. Conselho Nacional de Educação. Câmara de Educação Superior. Resolução CNE/CES no 15, de 13 de março. 2002. Institui Diretrizes Curriculares Nacionais do Curso de Graduação de Serviço Social. Brasília, 2002b. Disponível em:<http://portal.mec.gov.br/sesu/arquivos/ pdf/1502ServSocial.pdf $>$. Acesso em: 18 jun. 2013.

BRASIL. Ministério da Saúde; Ministério da Educação. Portaria interministerial $n^{\circ}$ 610, de março de 2002. Institui o Programa Nacional de Incentivo às Mudanças Curriculares para as Escolas Médicas. Brasilia, 2002c. 
Pressupostos pedagógicos das atuais propostas de formação superior em saúde no Brasil: origens históricas e fundamentos teóricos

BRASIL. Ministério da Saúde. Portaria № 198/GM/MS. Institui a Política Nacional de Educação Permanente em Saúde. Brasília, 2004. Disponível em: <http://dtr2001.saude.gov.br/sas/PORTARIAS/Port2004/ GM/GM-198. htm>. Acesso: 12 jul. 2012.

BRASIL. Ministério da Saúde. Ministério da Educação. Programa Nacional de Reorientação da Formação Profissional em Saúde - Pró-Saúde: objetivos, implementação e desenvolvimento potencial. Brasília: Ministério da Saúde, 2007.

BRASIL. Ministério da Saúde. PET-Saúde: Programa de Educação pelo Trabalho para a Saúde. Brasília: 2011.

BRIDGE, Edward Mervin. Pedagogía médica. Washington, D.C: Publicación Científica da Organización Panamericana de la Salud, n. 122, 1965.

CAMBI, Franco. História da pedagogia. São Paulo: Ed. UNESP, 1999. CHAVES, Mário; ROSA, Alice Reis. Educação médica nas Américas: o desafio dos anos 90. São Paulo: Cortez, 1990.

CHAVES, Mário et al. Revisitando o ideário e reconstruindo a proposta. In: ALMEIDA, Marcio José; FEUERWERKER, Laura; LLANOS, Manuel (Orgs.). Educação dos profissionais de saúde na América Latina: teoria e prática de um movimento de mudança. Tomo 1: Um olhar analítico. São Paulo: Hucitec; Buenos Aires: Lugar Editorial; Londrina: Ed. UEL, 1999. p. 165-183.

COUSINET, Roger. A educação nova. São Paulo: Companhia Editora Nacional, 1959.

CUTOLO, Luiz Roberto Agea; DELIZOICOV, Demétrio. Caracterizando a escola médica brasileira. Arquivos Catarinenses de Medicina, Florianópolis, v. 32, n. 4, p. 24-34, 2003.

DEWEY, John. Vida e educação. 10. ed. São Paulo: Melhoramentos. Rio de Janeiro: Fundação Nacional de Material Escolar, 1978.

DEWEY,_John. Democracia e educação. São Paulo: Editora Nacional, 1979 a. 
DEWEY, John. Experiência e educação. 3. ed. São Paulo: Editora Nacional, 1979b.

FEUERWERKER, Laura Camargo Macruz. O movimento mundial de educação médica: As Conferências de Edinburgh. Rio de Janeiros: Cadernos ABEM, Rio de Janeiro, v. 2, p. 30-38, 2006.

FEUERWERKER, Laura Camargo Macruz et al. O processo de construção e de trabalho da Rede UNIDA. Divulgação em saúde para debate, Rio de Janeiro, n. 22, p. 9-17, dez. 2000.

FREIRE, Paulo. Educação como prática da liberdade. 19. ed. Rio de Janeiro: Paz e Terra, 1989.

FUNDAÇÃO KELLOGG. Carta convite dos Projetos UNI às instituições de Ensino Superior. 991. Disponível em: <www.ccs.uel.br/prouni/docs/ BRASIL/LONDRINA/BR_LD_GES_06.pdf>. Acesso em: 10 mai. 2012.

KISIL, Marcos; CHAVES, Mário. Introdução ao programa UNI. In: (Orgs). Programa UNI: uma nova iniciativa na educação dos profissionais da saúde. Battle Creeck: Fundação Kellogg, 1994. p. 1-11.

LEHER, Roberto. Da ideologia do desenvolvimento à ideologia da globalização: a educação como estratégia do Banco Mundial para o alívio da pobreza. São Paulo, 1998. Tese (Doutorado em Educação) - Faculdade de Educação, Universidade de São Paulo, SP, 1998.

NEILL, Alessander Sutherland. Liberdade sem medo. São Paulo: Ibrasa, 1976.

OFICINA SANITÁRIA PANAMERICANA. Seminarios sobre la enseñanza de medicina preventiva. Washington D.C.: Publicações Científicas no 28. Mar. 1957. Disponível em: <http://hist.library.paho.org/ English/SPUB/40174.pdf>. Acesso em: 9 jan. 2012.

ORGANIZACIÓN PANAMERICANA DE LA SALUD. Primer Congreso Panamericano de Educación Médica. Boletín de la Oficina Sanitaria Panamericana (OSP), Washington, v. 32, n. 1, p. 35-36, ene. 1952. Disponível em: < http://hist.library.paho.org/Spanish/BOL/v32n1p35.pdf>. Acesso em: 3 mar. 2012. 
Pressupostos pedagógicos das atuais propostas de formação superior em saúde no Brasil: origens históricas e fundamentos teóricos

ORGANIZACIÓN PANAMERICANA DE LA SALUD. II Plan Decenal de Salud para las Americas: Informe final de la III Reunión Especial de Ministros de Salud de las Américas. OPAS/OMS: Washington, D.C. Enero, 1973. Disponível em: <http://hist.library.paho.org/English/OD/34900.pdf>. Acesso em: 12 dez. 2011.

\section{ORGANIZACIÓN PANAMERICANA DE LA SALUD. Evaluacion} de los Centro Panamericanos. Centro Latinoamericano de Tecnologia Educacional para la Salud (CLATES). Washington, D.C. 1983. Disponível em: < http:/hist.library.paho.org/spanish/GOV/CE/CE90_18.pdf $>$. Acesso em: 10 abr. 2012.

ORGANIZAÇÃO PAN-AMERICANA DA SAÚDE. Recomendações da II Conferência Mundial de Educação Médica. In: SANTANA, José Paranaguá; ALMEIDA, Márcio José de. Contribuições sobre a gestão de qualidade em educação médica. Série Desenvolvimento de Recursos Humanos. Washington, n. 7, p. 17-32, 1994. Disponível em: <www.opas.org.br/rh/ publicacoes/textos_apoio/cgqem_recomenda.pdf>. Acesso em: 10 abr. 2012.

ORGANIZAÇÃO MUNDIAL DE SAÚDE; UNICEF - FUNDO DAS NAÇÕES UNIDAS PARA A INFÂNCIA. Declaração de Alma-Ata. Conferência Internacional sobre Atenção Primária em Saúde. OMS; UNICEF, 1978.

PIRES-ALVES, Fernando Antonio. A cooperação interamericana em saúde na era do desenvolvimento: informação científica e tecnologias educacionais na formação de recursos humanos (1963-1983). 2011. Tese (Doutorado) - Casa de Oswaldo Cruz, Fundação Oswaldo Cruz, RJ, 2011.

SANTANA, José Paranaguá et al. Formação profissional em saúde: desafios para universidade. In: SANTANA, José Paranaguá; CASTRO, Janete Lima (Org.). Capacitação em desenvolvimento de recursos humanos de saúde: CADRHU. Natal: EDUFRN, 1999. p. 233-244

SAVIANI, Dermeval. Escola e democracia: teorias da educação, curvatura da vara, onze teses sobre educação e política. 25. ed. São Paulo: Cortez/ Autores Associados, 1991.

REDE UNIDA. Contribuição para as novas diretrizes curriculares dos cursos de graduação da área de saúde. Revista Olho Mágico, Londrina, n. 16, p. 11-35. abr./jun. 1998. 
RODRIGUES, Rosa Maria. Diretrizes curriculares para a graduação em enfermagem no Brasil: contexto, conteúdo e possibilidades para a formação. 2005. 256p. Tese (Doutorado) - Faculdade de Educação, Universidade Estadual de Campinas, Campinas, SP, 2005.

ROGERS, Carl. Liberdade para aprender. Belo Horizonte, MG: Inter Livros, 1971.

ROSA, Alice Reis. O componente acadêmico e os Projetos UNI. In: KISIL, Marcos; CHAVES, Mario (Orgs.). Programa UNI: uma nova iniciativa na educação dos profissionais da saúde. Battle Creeck: Fundação Kellogg, 1994. p. 25-36.

ZANOTTO, Maria Angélica do Carmo; DE ROSE, Tânia Maria Santana. Problematizar a própria realidade: análise de uma experiência de formação contínua. Educ. Pesqui. [online], São Paulo, v. 29, n. 1, p. 45-54. 2003. Disponível em: < http://www.scielo.br/pdf/ep/v29n1/a04v29n1.pdf > . Acesso em: 23 jul. 2012.

Solange de Fátima Reis Conterno - Universidade Estadual do Oeste do Paraná | Cascavel | PR | Brasil. Contato: solangeconterno@gmail.com Roseli Esquerdo Lopes - Universidade Federal de São Carlos São Carlos | SP | Brasil. Contato: relopes@ufscar.br

Artigo recebido em 26 de abril de 2015 e aprovado em 27 de maio de 2016. 